\title{
Collaborative Authorship in the Journal Literature: Perspectives for Academic Librarians Who Wish to Publish
}

\section{Alice Harrison Bahr and Mickey Zemon}

\begin{abstract}
Academic librarians, particularly college librarians, may increase their contributions to the professional literature through collaborative authorship. For example, university librarians, who published 69 percent of the articles in College \& Research Libraries and the Journal of Academic Librarianship between 1986 and 1996, contributed almost 90 percent of the coauthored research in those core journals. This study examines the increase in collaboration in the literature of academic librarianship and in other disciplines, explores the relationship between collaboration and article quality as well as author productivity, compares collaborative patterns of college and university librarians, and considers factors that lead to successful collaboration.
\end{abstract}

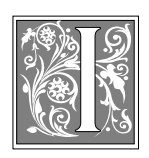

n 1997, the authors examined the extent to which college librarians published articles in two of academic librarianship's premier research journals. ${ }^{1}$ The results of their study confirmed that publication in the premier professional research literature is "primarily an accomplishment of university, not college, librarians." ${ }^{2}$ Of the 540 articles that college and university librarians published in College $\mathcal{E}$ Research Libraries (CERL) and the Journal of Academic Librarianship (JAL) between 1986 and 1996, college librarians contributed only fiftyfour, or 10 percent. ${ }^{3}$ That was about half of what might have been expected given that 22 percent of ACRL's members belong to the College Library Section and a comparable percentage of librarians were then at work in Baccalaureate I (BAI), Baccalaure- ate II (BAII), and Master's Degree II (MAII) Carnegie Classification institutions. ${ }^{4}$

\section{Current Study}

Although the earlier study confirmed that publication by college librarians was low compared with their numbers, it uncovered another significant finding: college librarians were less likely than their university counterparts to collaborate on journal articles. Yet, collaboration is the norm in many disciplines and, increasingly, evidence indicates that collaborative articles have a greater chance of being published.

This study examines the notable increase in coauthored articles in the core literature of academic librarianship and in other disciplines, reviews relevant research on collaboration, compares the collaborative patterns of university and college li-

Alice Harrison Bahr is Director of the Library at Spring Hill College; e-mail: bahr@azalea.shc.edu. Mickey Zemon is the Library Director at Emerson College; e-mail: ecl_maz@flo.org. 
brarians, and offers perspectives on what leads to successful collaboration. It extends research from the 1997 study by gathering data on the gender, number, and affiliation of university librarian coauthors, providing a basis for comparing results of studies of coauthorship in other disciplines.

\section{Methodology and Definitions}

A Microsoft Access database had been used previously to record both data and complete bibliographic information on articles published in CERL and JAL from 1986 to 1996 . A separate, linked table held data on articles authored by college librarians. For this study, the larger table of all other articles was expanded to identify the following: collaborative articles by university librarians, the number of collaborative partners for each article, and the status of each collaborative partner. The status of each collaborative partner was defined by one of four categories: university librarian, faculty member, library science faculty member, or other.

\section{Definition of Article}

As have most studies of authorship, this one includes full-length, substantive articles. It limits these even further, by including only articles by authors at U.S. academic institutions and by specifically excluding symposia contributions, reviews, reprints, brief commentaries, and two ongoing CERL series: "Selected Reference Books" and "Research Notes." Most references are to numbers of articles, not numbers of authors. Any article with even one college librarian author was counted as a college librarian publication.

\section{Journal Selection Rationale}

This study focuses on CERL and JAL because they are "by common consensus ... the major journals in academic librarianship" and also because existing self-studies of CERL provide useful comparative data. ${ }^{5}$ Their selection provides an excellent platform for enlarging both studies. Most important, as refereed journals using blind review, they hold significant weight for tenure and promotion decisions and their contributors most frequently are academic librarians. ${ }^{6}$

\section{Definition of College Library}

This paper uses the 1994 Carnegie Classification for institutions to determine whether authors worked at colleges or universities. If a librarian was employed at the time an article was published at a BAI, BAII or MAII institution, he or she was designated a college librarian author. ${ }^{7}$ A university librarian author was defined as an individual working at the time his or her article was published at a research university, doctoral university, or master's university or college (MAI) that annually awarded forty or more master's degrees in three or more disciplines. Institutions offering other degrees and professional and specialized schools were excluded.

\section{Increases in Collaborative Authorship}

Although library science journals are just beginning to note increases in co- and multiauthored articles, both types of articles have been dramatically transforming the literature of other disciplines for decades. At the beginning of the twentieth century, 80 percent of chemistry papers had one author; sixty years later, most had multiple authors. ${ }^{8}$ In the first decade of the twentieth century, 75 percent of biological and physical science papers had one author. ${ }^{9}$ By contrast, a 1997 report on the most frequently cited papers in biology concluded that "solo research performance, as represented by single-author papers, is near extinction ...."10

The same pattern emerged somewhat later in the social sciences. Between 1949 and 1979, multiauthored papers went from 34 to 64 percent in psychology. ${ }^{11}$ In 1963 , only 18 percent of articles in nine key anthropology journals had more than one author; twenty years later, it was 40 percent. ${ }^{12}$ Although only eight percent of papers in the American Economic Review were multiauthored in 1950, by 1993, the percent had increased to 54.9. ${ }^{13}$ Between 1895 and 1925, only one percent of articles in four core sociological journals were written by more than one author. ${ }^{14}$ How- 
ever, a current survey of key social science journals from 1984 to 1994 indicated that multiple authorship was now the "norm for sociological and psychological studies. ${ }^{15}$ By the 1990 s, one study indicated that 60 percent of the articles in four key criminology and criminal justice periodicals were multiauthored. ${ }^{16}$ Even in the health and physical recreation field, multiauthorship is now common. In eighteen respected journals, four had multiauthorship percentages of between 59 and 64 percent, and thirteen of the titles exceeded 50 percent. ${ }^{17}$

The same trends are now evident in library science. James L. Terry's study of authorship in $C \mathcal{E} R L$ reveals the notable increase in collaborative articles (see table 1). ${ }^{18}$

A more comprehensive study by Anne C. Weller, Julie M. Hurd, and Stephen E. Wiberley Jr. found that 45 percent of articles by U.S. academic librarians and deans in thirty-two peer-reviewed journals between 1993 and 1997 had two or more authors. ${ }^{19}$

\section{Collaboration and Publication Acceptance}

Because journals are publishing increasing numbers of collaborative articles, these articles have a greater chance of being accepted for publication. Studies indicate a relationship between these two factors, particularly in fields where the majority of publications are multiauthored. In fact, one pair of researchers noted that multiauthored papers in The Physical Review had a 95 percent acceptance rate. ${ }^{20}$

An examination by Peter Hernon, Allen Smith, and Mary Bailey Croxen of papers submitted to CERL for an eleven-year period, from 1980 to 1991, indicated that single authors submitted more papers, but that papers by multiple authors were published more frequently. ${ }^{21}$ Stanley Presser's study, though limited to one social psychology journal, found that "collaboration is associated with more favourable review of papers," both those "from Ph.D. departments and non-Ph.D. departments." ${ }^{22} \mathrm{He}$ noted that the relation was somewhat stronger in the latter, which suggests "that
TABLE 1

Increase in Coauthorship in $C \& R L$

Single Authorship, 1939-1944

\begin{tabular}{c} 
Time Period $\quad \begin{array}{c}\% \text { of Articles with } \\
\text { No Coauthors }\end{array}$ \\
\hline
\end{tabular}

\begin{tabular}{ll}
\hline $1939-44$ & 95.7 \\
$1945-49$ & 95.6 \\
$1950-54$ & 93.5 \\
$1955-59$ & 92.7 \\
$1960-64$ & 94.0 \\
$1965-69$ & 85.9 \\
$1970-74$ & 79.1 \\
$1975-79$ & 72.7 \\
$1980-84$ & 68.1 \\
$1985-88$ & 54.1 \\
$1989-94$ & 40.5
\end{tabular}

collaboration is more important in minor departments ...." ${ }^{23}$ This suggested to Mary Frank Fox and Catherine A. Faver that "able researchers, in minor rather than major institutions, are especially likely to collaborate." ${ }^{\prime 24}$ Although, in practice, this is not the case in academic libraries, it suggests that researchers in smaller institutions might benefit the most from collaboration.

\section{Collaboration and Article Quality}

If journals are more likely to accept papers with more than one author and the percentage of published multiauthored papers increasingly outweighs that of singleauthored ones, one assumes that the quality of these papers is better. Numerous studies have tried to prove this association by defining quality in different ways, including prestige of a journal, peer and/or editorial assessments of papers, frequency of citation, funding, and type of article.

\section{Prestige of a Journal}

As indicated above, prestigious journals in several fields publish increasingly higher percentages of collaborative papers. Separating articles written by seventyeight full-time, tenure-track Pennsylvania State University librarians into three categories-nonrefereed articles, refereed articles, and articles from the "core" of academic library literature, Richard L. Hart 
was able to show that the increasing quality of articles reflected an increase in the amount of collaboration. ${ }^{25}$ Although excellent papers appear in both refereed and nonrefereed journals, the former undergo more extensive evaluation.

\section{Peer and Editorial Assessments}

There is good evidence that collaborative papers require less revision. Gibson's 1988 doctoral dissertation indicated a strong statistical relationship between multiauthored papers and fewer comments on manuscripts, and Presser noted that articles with two or more authors were more likely to be accepted, and much more likely to be asked to be resubmitted, by editors at Social Psychology Quarterly. ${ }^{26,27}$

Not only are university librarians the greatest contributors to the field's premier research journals, but they also are its most significant collaborators.

\section{Frequency of Citation}

The most convincing evidence that citations are valid indicators of quality came from Stephen M. Lawani and Alan E. Bayer, who compared the number of citations that first- and second-order papers in the Year Book of Cancer received to the number of citations that general papers in Biological Abstracts received. They found that average-order papers received 55.7 percent of citations, but second- and firstorder papers, generally recognized as the best in the field, received 72.7 and 73.7 percent, respectively. ${ }^{28}$ By proving the relationship between quality and citation frequency, Lawani and Bayer laid the groundwork for other studies that investigated citation frequency for collaborative articles. One such study included a ten-year check of citations to a sampling of articles from three core sociological journals. The conclusions of that study were that singleauthored articles were less likely to be cited than multiauthored ones. ${ }^{29}$

\section{Funding}

Some studies have suggested a connection between funding and citation frequency. Logan Wilson noted that funded studies received more citations that those that were turned down and completed without funding. ${ }^{30}$ Basing part of his work on the idea that funded research would be superior to nonfunded research, Hart examined funded (only 10\% of the total articles) and nonfunded articles in forty-one library science journals for 1996 . He concluded that collaboration was more prevalent among authors of funded research. ${ }^{31}$

\section{Type of Article}

If one associates quality with statistical sophistication, there is ample evidence that quantitative articles evidence the greatest collaboration. Coding full-length articles in three key political science journals from 1950 to 1996 as either theoretical or empirical, Bonnie S. Fisher and colleagues found that "for any given year, empirical articles were more likely to be multiple authored ...."32 Fisher and colleagues had found pretty much the same results in an earlier study of criminal justice, sociology, and political science journals. ${ }^{33}$ Similarly for economics, Hudson determined that "multi-authorship is more prevalent in the more quantitative journals." 34

\section{Collaboration and Author Productivity}

Pinning down the relationship between collaboration and productivity is difficult. On the surface, it seems reasonable to assume that by sharing work each person can produce more. However, there are wide-ranging variables, and except in a few cases, it is impossible to determine whether a writer could have been even more productive in a different mode. The clearest evidence of a relationship came from the field of chemistry. Derek J. de Solla Price and Donald Beaver discovered that chemists working alone or with another author wrote four papers in five years, but those working with more than twelve collaborators each wrote fourteen articles. ${ }^{35}$ Analyzing chemists' publication styles, Alan E. Bayer and John C. Smart determined that the most likely authors to 
collaborate and those who wrote equal numbers of single- and multiauthored publications also were most likely to remain productive throughout their careers. ${ }^{36}$

The relationship between collaboration and productivity appears to rest on the number of collaborators. The greater the number of collaborators, the greater the potential for increased productivity. Indeed, a recognized trend in collaboration is the increase of multiauthorship (more than two authors). Zhang Haiqi noted that often-cited papers in biology had more authors, typically between six or seven, than less-cited articles. ${ }^{37}$ A study by James W. Endersby of thirteen social sciences journals from 1984 to 1994 summed up this pattern well by noting that the "trend over time within each profession is toward a gradual increase in the average number of authors per article." ${ }^{38}$ Of course, not all research and not all fields at present mandate a research process that is highly collaborative. However, the trend toward greater numbers of collaborators in growing in the sciences and social sciences.

\section{Findings}

Not only are university librarians the greatest contributors to the field's premier research journals, but they also are its most significant collaborators. Of the 399 articles in CERL from 1986 to 1996, 159 (40\%) were written collaboratively. ${ }^{39}$ Of those 159 collaborative articles, 133 were written by university librarians. Consequently, 84 percent of collaborative articles were by university librarians. Because university librarians authored a total of 276 articles, of which 133 had more than one author, 48 percent or almost half of all articles contributed were collaborative efforts. Collaboration is slightly less in $J A L$, with only eighty-eight $(29 \%)$ of the 302 articles multiauthored. Again, however, university librarians were the most significant collaborators, contributing seventy-eight of the eighty-eight articles, or 89 percent. Certainly, university librarians provide a good model for examining collaborative patterns.

College librarians collaborate much less frequently than their university library counterparts do. They contributed fifty-four articles to both journals, only eighteen (33\%) of which were collaborative. Between 1993 and 1996, the percentage of collaborative articles in JAL and $C \mathcal{E} R L$ reached and maintained fairly high levels, yet there was no steady observable incidence of increased collaboration among college librarians for those years. Although table 2 shows increases for university librarians, college librarians published just ten collaborative articles during these years: two in 1993, five in 1995, two in 1995, and one in 1996.

\section{Number of Authors}

Although the social science fields show increasing evidence of articles with more than two authors, the greatest number of collaborative papers in these fields involve just two persons. ${ }^{40}$ The same pattern is evident in JAL and CERL. Of the 133 collaborative articles by university librarians in CERL, 96 (72\%) were written by two authors, $27(20 \%)$ by three authors, and only six $(5 \%)$, three $(2 \%)$, and one ( $1 \%$ ) had four, five, or six authors, respectively. In recent years, the number of articles by more than two authors has not increased.

\begin{tabular}{|ccc|}
\hline \multicolumn{3}{|c|}{ TABLE 2} \\
Increase in Percent of Collaboration in $\boldsymbol{C} \boldsymbol{\&} \boldsymbol{R} \boldsymbol{L}$ and $\boldsymbol{J} \boldsymbol{A L}$ from $\mathbf{1 9 9 3}$ to $\mathbf{1 9 9 6}$ \\
\hline \hline YEAR & $\begin{array}{c}\boldsymbol{C} \boldsymbol{\&} \boldsymbol{R} \boldsymbol{L}: \text { Collaborative Articles } \\
\text { by University Librarians (\%) }\end{array}$ & $\begin{array}{c}\boldsymbol{J} \boldsymbol{A} \boldsymbol{L}: \text { Collaborative Articles } \\
\text { by University Librarians (\%) }\end{array}$ \\
\hline 1993 & 40 & 60 \\
1994 & 47.62 & 65.22 \\
1995 & 43.48 & 40 \\
1996 & 60 & 40.91 \\
\hline
\end{tabular}


Between 1986 and 1991, fourteen articles were written by more than two authors and fifteen between 1991 and 1996. There is no evidence of increasing numbers of articles with more than three authors.

The figures are comparable in $J A L$. Sixty-one (78\%) articles had two authors, fourteen $(18 \%)$ had three, two $(3 \%)$ had four, and only one (1\%) had five. Between 1986 and 1991 and between 1991 and 1996, the number of articles with three authors rose from six to eight.

The same pattern holds true for collaborative articles by college librarians. Fourteen (78\%) had two authors and four $(22 \%)$ had three. No collaborative articles had more than three authors.

\section{Gender}

Analysis by gender indicates similarities between university and college librarian authors (table 3). Some of these are evidenced in other disciplines. Fisher's examination of three key political science titles from 1950 through 1996 indicated that for women, the most common form of collaboration was cross-sex collaboration. ${ }^{41}$ Cross-sex collaboration is also the typical pattern among college and university librarian authors. They share two other commonalities, as well. First, in all cases and for both journals, the smallest category of collaborators is all male. As collaborators, men are more likely to work with women than with men. Second, in all cases and for both journals, women are more likely to collaborate than men. This is

\begin{tabular}{|c|c|c|c|}
\hline \multicolumn{4}{|c|}{$\begin{array}{c}\text { TABLE } 3 \\
\text { Collaborative Articles }\end{array}$} \\
\hline Category & $\begin{array}{c}\text { University } \\
\text { Authors } \\
C \& R L \\
\text { (No./\%) } \\
\end{array}$ & $\begin{array}{c}\text { University } \\
\text { Authors } \\
\boldsymbol{J} A \boldsymbol{L} \\
\text { (No./\%) } \\
\end{array}$ & $\begin{array}{c}\text { College Librarians } \\
\text { in } C \& R L \\
\text { and } J A L \\
(\text { No. } / \%) \\
\end{array}$ \\
\hline Female Only & $40 / 30 \%$ & $30 / 39 \%$ & $4 / 22 \%$ \\
\hline $\begin{array}{l}\text { Female/Male } \\
\text { (females listed first) }\end{array}$ & t) $36 / 27 \%$ & $12 / 15 \%$ & $6 / 33 \%$ \\
\hline $\begin{array}{l}\text { Female/Male } \\
\text { (males listed first) }\end{array}$ & $29 / 22 \%$ & $14 / 18 \%$ & $6 / 33 \%$ \\
\hline Male Only & $28 / 21 \%$ & $22 / 28 \%$ & $2 / 11 \%$ \\
\hline Total Articles & 133 & 78 & 18 \\
\hline
\end{tabular}

borne out in a 1999 study of publications by Illinois academic librarians. ${ }^{42}$ Moreover, women are more likely to collaborate with women than men are with men. This is true in other fields, as well-namely, social work and political science. ${ }^{43}$

\section{Collaborative Partners}

The pattern of similarities holds true for college and university librarians again when the issue is who collaborates with whom (table 4). For university librarians, the most common partner is another university librarian. Of the 185 authors contributing the 133 collaborative articles in CERL, 124 (67\%) were university librarians, nineteen $(10 \%)$ were faculty, eighteen $(10 \%)$ were library science faculty, and twenty-four $(13 \%)$ were designated as other, a catchall for vendors, librarians from junior colleges or public libraries, and so on. The pattern persists for JAL. Of the ninety-nine authors responsible for seventy-eight collaborative articles, seventythree $(74 \%)$ were university librarians, nine (9\%) were faculty, eight ( $8 \%$ ) were library science faculty, and nine (9\%) were other.

College librarians demonstrate a comparable pattern. The eighteen collaborative articles they wrote for $J A L$ and $C \mathcal{E} R L$ had a total of forty authors, eighteen college librarians and twenty-two collaborative partners. Of the twenty-two partners, eight were university librarians, five were college librarians, six were faculty, one was library science faculty, and two were other.

\section{The Collaborative Process}

Despite the increase in coauthored articles, little in the literature advises prospective coauthors on ways to work together successfully. The hard sciences, where researchers employed collaborative techniques early on, have ad- 
dressed one aspect of the collaborative process in detaildetermining credit fairly, a particularly difficult problem when the number of collaborators is large. ${ }^{44}$

What prerequisites should academic librarians consider before they de-

TABLE 4

Collaborative Partners: Who Collaborates with Whom?

\begin{tabular}{|c|c|c|c|}
\hline Category & $\begin{array}{c}C \& R L \\
\text { (No.) }\end{array}$ & $\begin{array}{l}J A L \\
\text { (No.) }\end{array}$ & $\begin{array}{c}\text { College Librarians } \\
\text { in } C \& R L \\
\text { and } J A L(\text { No.) }\end{array}$ \\
\hline University Librarians & 124 & 73 & 8 \\
\hline College Librarians & & & 23 \\
\hline Faculty & 19 & 9 & 6 \\
\hline Library Science Faculty & 18 & 8 & 1 \\
\hline Other & 24 & 9 & 2 \\
\hline Total No. of Authors & 185 & 99 & 40 \\
\hline
\end{tabular}
cide to collaborate?

First, they should select coauthors carefully. Fox and Faver identify the single, most important step in successful collaboration as choosing "collaborative partner(s) wisely." 45 They point out that picking collaborators involves assessing both personal and intellectual factors. Under personal factors, they mention a need "to assess the primacy of work for each." ${ }^{\prime 46}$ In other words, partners must have a deep interest in the topic to be researched and a commitment to fulfill their share of the responsibilities, in addition to compatible work habits. Collaborators also must have the subject expertise and skills needed for the project, which, in many cases, should complement rather than duplicate those of the others.

Second, collaborators should make their expectations clear to one another from the start. Joy Thomas recommended devising an unambiguous work plan, and Susan L. Boykoff suggested creating a coauthorship agreement that details who does the abstract, sends the query letter, does the first and subsequent drafts, and prepares the tables. ${ }^{47,48}$ Although a written document is no guarantee of success, and may indeed deter some from entering into such arrangements, collaborators must make some decisions before work begins. They must determine together what they are going to do (the focus of project), who is going to do what tasks, what the time line is going to be, to whom they are going to send the completed paper for publication, and how authorship credit is to be acknowledged. Agreeing in advance about what software pro- grams, e-mail systems, and manuscript revision techniques will be used also does much to prevent misunderstandings. Of course, some aspects of the collaborative experience will have to be negotiated later on, so there must be enough leeway to add new responsibilities, with a resultant change in assigning publication credit.

Third, collaborators should recognize that the collaborative process requires certain behaviors from those who enter into it. Fox and Faver noted that "In a collaborative project, the primary principle of

\section{Collaboration always requires enormous give and take: partners who are willing to give up some control over the product of their labors and flexible enough to adjust to the needs of their coauthors.}

scheduling is co-operation ...." ${ }^{49}$ They also noted that certain characteristics are essential for success, including "communication, honesty, trust, and an absence of 'bluffing. ${ }^{\prime \prime \prime 50}$ Collaborators should add a good measure of patience and tolerance to this list. Working together is likely to take more time, not less. Coauthors must consult frequently throughout their project and spend extra time working out differences of opinion or approach. Long-distance collaboration is even more difficult because many aspects of the process are done more easily in person rather than at a distance-for example, providing criticism to and receiving it from others. The ability to e-mail attachments and fax materials back and forth 
greatly facilitates such feedback, but the nuances of face-to-face communication are lost in the transmission. Collaboration always requires enormous give and take: partners who are willing to give up some control over the product of their labors and flexible enough to adjust to the needs of their coauthors. In the long run, the collaborators' individual efforts must be merged into a seamless paper that communicates in one consistent style and voice.

\section{Conclusions}

As evidenced in the sciences and social sciences, collaboration encourages author productivity and enhances article quality. As research becomes more quantitative, collaboration increases. Patel referred to the increase in collaboration as part of a process following specialization "in which a discipline is reintegrated at a higher level." ${ }^{51}$ Collaboration offers academic librarians an opportunity to participate in this higher level.

Collaboration brings other benefits as well, not the least of which is alleviating the professional isolation described by Fox and Favor in their summative piece on the benefits and drawbacks of collaboration. ${ }^{52}$ Given the time research requires, the increased likelihood of publication for collaborative articles, and the evolving collaborative focus in all disciplines, partnering provides increased opportunity for contributing to the professional literature. ${ }^{53}$
Specifically for college librarians, who publish proportionately less than their numbers, collaboration offers a way of meeting editors' requests for more submissions. The past editor of $C \mathcal{E} R L$ and $J A L$, Gloriana St. Clair, remarked: "In my time as editor, I was always searching for more articles about colleges and community colleges." ${ }^{54}$ In her closing editorial in $C \mathcal{E} R L$, she recounted: "I have worked with college authors to bring every possible submission into the journal. However, submissions by college librarians and about college library problems continue to be limited." 55 The current CERL editor, Donald E. Riggs, also has noted: "The bulk of manuscripts received come from university libraries. However, there are many exciting developments occurring in community and four-year colleges, and these two institutions are woefully underrepresented in the literature on academic libraries/librarianship." 56

Collaborative contributions from librarians and others at smaller institutions would focus attention on issues of particular significance to these institutions, broaden the literature, and help to determine what, if any, difference size has on services, collections, and staffing. Accordingly, college and university librarians should consider collaboration not only as a means of increasing their productivity, but also of broadening the topical coverage in the field's premier research literature.

\section{Notes}

1. Mickey Zemon and Alice Harrison Bahr, "An Analysis of Articles by College Librarians," College $\mathcal{E}$ Research Libraries 59 (Sept. 1998): 422-32. That study was prompted by editors' comments about the paucity of college librarians' contributions to the literature and by a desire to gauge what, if any, impact the work of the Research for College Librarianship Committee (RCLC) might have had on encouraging more research and publication by college librarians. Established in 1992 by ACRL's College Libraries Section, the RCLC has held roundtables at all national ACRL conferences, sponsored panel discussions at midwinter ALA conferences, and published InPrint, Publishing Opportunities for College Librarians.

2. Ibid., 422 .

3. Ibid., 425 .

4. Ibid.

5. Mary K. Sellen, "Bibliometrics in Information Science: A Citation Analysis of Two Academic Library Journals," College E Research Libraries 45 (Mar. 1984): 129.

6. Watson's study of authors' affiliations in eleven library science journals from 1979 to 1983 concluded that "academic librarian authors are the primary contributors to College $\mathcal{E}$ Research Libraries and to the Journal of Academic Librarianship" (337). Krausse found that the percent of 
articles by authors from academic libraries was highest for JAL and CERL (129).

7. "Carnegie Foundation's Classification of 3,600 Institutions of Higher Education," The Chronicle of Higher Education (Apr. 6, 1994): A18. Since the 1987 classifications were revamped in 1994, their equivalents are as follows: BAI-Primarily undergraduate, emphasis on baccalaureate programs, selective in admissions, and awards 40 percent of baccalaureate degrees in the liberal arts (1987 equivalent-LAI); BAII-Primarily undergraduate, emphasis on baccalaureate programs, less selective in admissions, and awards less than 40 percent of baccalaureate degrees in the liberal arts (1987 equivalent-LAII); and MAII-Offers a full range of baccalaureate programs, committed to graduate education through the master's degree, and awards 20 or more master's degrees in one or more disciplines (1987 equivalent-CompII).

8. James W. Endersby, "Collaborative Research in the Social Sciences: Multiple Authorship and Publication Credit," Social Science Quarterly 77, no. 2 (June 1996): 375-92.

9. Anne E. Austin and Roger G. Baldwin, Faculty Collaboration: Enhancing the Quality of Scholarship and Teaching. ASHE-ERIC Higher Education Report No. 7 (Washington, D.C.: George Washington Univ., School of Education and Human Development, 1991), 25.

10. Zhang Haiqi, "Brief Communication: More Authors, More Institutions, and More Funding Sources: Hot Papers in Biology from 1991 to 1993," Journal of the American Society for Information Science 48, no. 7 (July 1997): 663.

11. Austin and Baldwin, Faculty Collaboration, 3.

12. Jin M. Choi, "An Analysis of Authorship in Anthropology Journals, 1963 \& 1983," Behavioral Social Sciences Librarian 6, no. 3/4 (1988): 88.

13. John Hudson, "Trends in Multi-authored Papers in Economics," Journal of Economic Perspectives 10, no. 3 (summer 1996): 153.

14. Mark Oromaner, "Collaboration and Impact: The Career of Multi-authored Publications," Social Science Information 14, no. 1 (1975): 147.

15. Endersby, "Collaborative Research in the Social Sciences," 378.

16. Bonnie S. Fisher et.al, "Trends in Multiple-authored Articles in Criminology and Criminal Justice: A Comparative Analysis," Journal of Criminal Justice Education 9, no. 1 (spring 1998): 26.

17. Darrell Crase and Frank D. Rosato, "Single vs. Multiple Authorship in Professional Journals," JOPHERD 67, no. 3 (Sept. 1992): 29.

18. James L. Terry, "Authorship in College \& Research Libraries Revisited: Gender, Institutional Affiliation, Collaboration," College \& Research Libraries 57 (July 1996): 379-81.

19. Ann C. Weller, Julie M. Hurd, and Stephen E. Wiberley Jr., "Publication Patterns of U.S. Academic Librarians from 1993 to 1997," College \& Research Libraries 60, 4 (July 1999): 357.

20. Martha A. Harsanyi, "Multiple Authors, Multiple Problems-Bibliometrics and the Study of Scholarly Collaboration: A Literature Review," Library \& Information Science Research 15, no. 4 (fall 1993): 332.

21. Peter Hernon, Allen Smith, and Mary Bailey Croxen, "Publication in College \& Research Libraries: Accepted, Rejected, and Published Papers, 1980-1991," College \& Research Libraries 54 (July 1993): 311.

22. Stanley Presser, "Collaboration and the Quality of Research," Social Studies of Science 10 (1980): 97.

23. Ibid.

24. Mary Frank Fox and Catherine A. Faver, "Independence and Cooperation in Research: The Motivations and Costs of Collaboration," Journal of Higher Education 55, no. 3 (May/June 1984): 350.

25. Richard L. Hart, "Collaborative Publication by University Librarians: An Exploratory Study." Unpublished manuscript.

26. Crase and. Rosato, "Single vs. Multiple Authorship in Professional Journals," 28.

27. Presser, "Collaboration and the Quality of Research," 96.

28. Stephen M. Lawani and Alan E. Bayer, "Validity of Citation Criteria for Assessing the Influence of Scientific Publication: New Evidence with Peer Assessment," Journal of the American Society for Information Science 34, no. 1 (1983): 59-66.

29. Oromaner, "Collaboration and Impact," 152.

30. Logan Wilson, American Academics (New York: Oxford Univ. Pr., 1979), 247.

31. Richard Hart et.al, "Funded and Non-Funded Research: Characteristics of Authorship and Patterns of Collaboration in the 1986 Library and Information Science Literature," Library $\mathcal{E}$ Information Science Research 12, no. 1 (Jan./Mar. 1990): 71-86.

32. Bonnie S. Fisher et.al, “How Many Authors Does It Take to Publish an Article: Trends and Patterns in Political Science," PS: Political Science \& Politics 31, no. 4 (Dec. 1998): 851.

33. —_ "Trends in Multiple-authored Articles in Criminology and Criminal Justice," 32.

34. Hudson, "Trends in Multi-authored Papers in Economics," 155.

35. Derek J. de Solla Price and Donald Beaver, "Collaboration in an Invisible College," American Psychologist 21 (1966): 1011-18.

36. Alan E. Bayer and John C. Smart, "Career Publication Patterns and Collaborative 'Styles' 
in American Academic Science," Journal of Higher Education 62, no. 6 (Nov./Dec. 1991): 613-36.

37. Haiqi, "Brief Communication," 663.

38. Endersby, "Collaborative Research in the Social Sciences," 382.

39. This is less of an increase in collaborative articles than Terry's article found, but the discrepancy results from the definition of article used for this study. Whereas both studies excluded book reviews and brief news items, this one also excluded two popular series, as well as articles with authors in non-U.S. institutions.

40. Endersby, "Collaborative Research in the Social Sciences," 382.

41. Fisher et al, "How Many Authors Does It Take to Publish an Article," 851.

42. Kathleen E. Joswick, "Article Publication Patterns of Academic Librarians: An Illinois Case Study," College \& Research Libraries 60 (July 1999): 340-49.

43. — . and J. Krysik, "Research Note: Women Authors in Social Work Journals," Social Work Research 18, no. 3 (Sept. 1994): 186-92.

44. Richard Horton and Richard Smith's commentary, "Signing Up for Authorship," Lancet 347, 9004 (Mar. 23, 1996): 347, explains the problem of assigning credit in medical articles by mentioning the National Library of Medicine's decision to list the first twenty-four authors and the last author of articles instead of the first six only. The problem is a major concern and has led to conferences on how do define authorship in a discipline in which articles can have in excess of one hundred authors. See Drummond Rennie, M.D., Veronica Yank, and Linda Emanuel, M.D., Ph.D., "When Authorship Fails: A Proposal to Make Contributors Accountable," JAMA 278, no. 7 (Aug. 20, 1997): 579-85, and Anne Hudson Jones, "Is the System Really Broken? (Assigning Authorship to Medical Research Articles)," Lancet 352, no. 9131 (Sept. 12, 1998): 894. Other difficulties associated with collaboration are pointed out in: Robert Wood, "A Personal Commentary on the Perils of Multiple Authorship Even Among Friends," Urban Affairs Review 30, no. 5 (May 1995): 687-89; Rennie, Yank, and Emanuel, "When Authorship Fails"; David L. Wheeler, "A Bitter Feud over Authorship," Chronicle of Higher Education 41, no. 38 (June 2, 1995): A8, A12.

45. Fox and Faver, "The Process of Collaboration in Scholarly Research," Scholarly Publishing 13, no. 1 (Oct. 1982): 328.

46. Ibid., 329.

47. Joy Thomas, Collaborative Writing, or, Is Half a Loaf Wroth the Stomach Ache? ERIC Document 410776 (Washington, D.C.: U.S. Department of Education, Office of Educational Research and Improvement, 1977), 6.

48. Susan L. Boykoff, "Coauthorship: Collaboration without Conflict," American Journal of Nursing 89, no. 9 (Sept. 1989): 1164.

49. Fox and Faver, "The Process of Collaboration in Scholarly Research," 336.

50. Ibid., 329.

51. Harsanyi, "Multiple Authors, Multiple Problems," 326.

52. Fox and Faver, "Independence and Cooperation in Research," 350.

53. Hart, "Scholarly Publication by University Librarians: A Study at Penn State," College $\mathcal{E}$ Research Libraries 60 (Sept. 1999): 454-62.

54. Gloriana St. Clair, "Steps toward Writing a Sure Thing," Library Administration \& Management 11 (winter 1997): 5.

55. ㄴ "Editorial: Endings and Beginnings," College \& Research Libraries 57 (May 1996): $210-11$.

56. Donald E. Riggs, "Editorial: Editor's Observations," College \& Research Libraries 58 (Nov. 1997): 496-97. 